\title{
BMJ Open Association of occupation with the daily physical activity and sedentary behaviour of middle-aged workers in Korea: a cross-sectional study based on data from the Korea National Health and Nutrition Examination Survey
}

\author{
Joo Hye Sung (D) , ${ }^{1}$ Se Rhim Son, ${ }^{2}$ Seol-Hee Baek, ${ }^{1}$ Byung-Jo Kim (D) ${ }^{1,3}$
}

To cite: Sung JH, Son SR, Baek S-H, et al. Association of occupation with the daily physical activity and sedentary behaviour of middle-aged workers in Korea: a crosssectional study based on data from the Korea National Health and Nutrition Examination Survey. BMJ Open 2021;11:e055729. doi:10.1136/ bmjopen-2021-055729

- Prepublication history and additional supplemental material for this paper are available online. To view these files, please visit the journal online (http://dx.doi.org/10.1136/ bmjopen-2021-055729).

Received 22 July 2021 Accepted 22 0ctober 2021

Check for updates

(c) Author(s) (or their employer(s)) 2021. Re-use permitted under CC BY-NC. No commercial re-use. See rights and permissions. Published by BMJ.

${ }^{1}$ Department of Neurology, Korea University Anam Hospital, Korea University College of Medicine, Seoul, South Korea

${ }^{2}$ Department of Biostatistics, Korea University College of Medicine, Seoul, South Korea ${ }^{3}$ BK21FOUR R\&E Center for Learning Health Systems, Korea University, Seoul, South Korea

Correspondence to

Dr Byung-Jo Kim;

nukbj@korea.ac.kr

\section{ABSTRACT}

Objectives The WHO recommends that adults engage in regular moderate-to-vigorous physical activities (MVPAs) and muscle-strengthening activities (MSA), and minimise sedentary behaviour. This study aimed to determine the association of occupation with MVPA, MSA and sedentary behaviour in middle-aged Korean workers.

Design and setting A cross-sectional study using data from the seventh Korea National Health and Nutrition Examination Survey (2016-2018).

Participants Workers aged between 40 and 69 years in Korea $(n=6359)$.

Outcome measures Population-weighted proportions not meeting the MVPA ( $<150 \mathrm{~min} /$ week) and MSA ( $<2$ days/ week) guidelines, and with high sedentary behaviour ( $>7$ hours/day) were calculated, and their associations with sociodemographic and work-related variables were assessed using multiple logistic regression analyses. Additionally, the estimated time spent on MVPA, MSA and sedentary behaviour according to the occupation categories (white-collar, pink-collar and blue-collar) was calculated using analysis of covariance (ANCOVA).

Results The MVPA level did not show a significant difference across the occupation categories. Blue-collar workers showed significantly lower MSA participation than white-collar and pink-collar workers (male, $p=0.006$; female, $p=0.004$; by ANCOVA). High sedentary behaviour was significantly associated with white-collar occupations $(p<0.001$ by ANCOVA). Longer working hours were negatively associated with MVPA $(0 R=1.01,95 \% \mathrm{Cl} 1.01$ to 1.02 ) and $\mathrm{MSA}(\mathrm{OR}=1.01,95 \% \mathrm{Cl} 1.00$ to 1.02). Workers with higher stress were less likely to participate in MSA (male: $\mathrm{OR}=1.43,95 \% \mathrm{Cl} 1.10$ to 1.86 ; female: $\mathrm{OR}=1.39$, $95 \%$ Cl 1.08 to 1.80). Self-employed workers showed lower MVPA levels than employees (male: $\mathrm{OR}=1.26,95 \%$ $\mathrm{Cl} 1.09$ to 1.47 ; female: $\mathrm{OR}=1.36,95 \% \mathrm{Cl} 1.13$ to 1.64 ). Daily workers compared with full-time workers $(\mathrm{OR}=0.38$, $95 \% \mathrm{Cl} 0.24$ to 0.59 ) and temporary workers compared with regular workers $(\mathrm{OR}=0.75,95 \% \mathrm{Cl} 0.59$ to 0.95 ) were associated with less sedentary behaviour in men. Conclusion A number of work-related factors were associated with PA levels and sedentary behaviour in

\section{STRENGTHS AND LIMITATIONS OF THIS STUDY}

$\Rightarrow$ This is the first study in Korea to investigate moderate-to-vigorous physical activity (MVPA) and MSA participation and sedentary behaviour concurrently across occupation categories using national representative data.

$\Rightarrow$ This study comprehensively investigated the association of occupation with PA level and sedentary behaviour regarding various socioeconomic confounding factors.

$\Rightarrow$ This study assessed the MVPA level of three domains (occupational, transportation and leisure time) and sedentary behaviour together to estimate overall physical activity status accurately.

$\Rightarrow$ The MVPA level, MSA level and degree of sedentary behaviour were analysed not only as dichotomous variables ('meeting the MVPA or MSA guideline' or 'not meeting the MVPA or MSA guideline', 'high sedentary' or 'low sedentary') but also as continuous variables (time spent on MVPA, MSA and sedentary behaviour).

$\Rightarrow$ Since the study design was cross-sectional, causality cannot be inferred.

middle-aged workers. The workplace is one of the critical elements to intervene in health promotion strategies.

\section{INTRODUCTION}

Physical inactivity is a worldwide public health problem and is responsible for about $6 \%-10 \%$ of the global burden of major chronic noncommunicable diseases. ${ }^{1}$ Until recently, physical activity $(\mathrm{PA})$ recommendations primarily focused on moderate-to-vigorous physical activity (MVPA). ${ }^{2}$ However, based on recent evidence, WHO's PA guidelines for public health now include muscle-strengthening activities (MSAs) in addition to MVPA. ${ }^{3}$ MSA provides additional metabolic health benefits ${ }^{4}$ 
and prevents sarcopenia. ${ }^{5}$ Moreover, there are cumulative health benefits by combining MVPA and MSA. ${ }^{67}$ Meeting guidelines for both activities compared with meeting the guideline for only one was associated with a lower risk of all-cause mortality in cohort studies. ${ }^{8}$

In addition, sedentary behaviour has recently emerged as a potential independent risk factor distinct from insufficient PA for poor health. ${ }^{9}$ The WHO guidelines state that the amount of time spent in sedentary should be limited and replaced with PA of any intensity. Previous large cohort studies have shown the detrimental effects of sedentary behaviour on all-cause mortality, ${ }^{10}$ metabolic syndrome, cardiovascular disease ${ }^{10} 11$ and mental health. ${ }^{12}$ The association between prolonged sitting and adverse health outcomes remained significant even after adjusting for aerobic exercise time, indicating that people should be active daily and limit their sedentary time for optimal health benefits. ${ }^{9} 1013$

Among the various socioeconomic factors related to $\mathrm{PA}$, one of the prime determinants might be occupation. People spend most of their lives employed, and occupation largely influences people's activities, not only during work hours but also during their leisure time. Some studies have focused on assessing PA levels in association with occupation using representative national data. ${ }^{14-21}$ However, most of the earlier studies did not focus concurrently on types of PA, such as MVPA and MSA, and sedentary behaviours, and analyses were limited to either work time or leisure time. ${ }^{14-1721}$ Each domain of MVPA might have different implications on health, as increasing evidence shows that occupational physical activity (OPA) and leisure-time physical activity (LTPA) have contrasting health effects, so-called PA health paradox. ${ }^{22}$ Therefore, this study aimed to investigate the middle-aged workers' overall participation in MVPA, MSA and sedentary behaviour according to sociodemographic and workrelated factors. The MVPA level was investigated not only in total but also by each domain (ie, occupational, transportation and leisure time).

\section{MATERIALS AND METHODS}

\section{Data collection and participants}

This study was based on data from the seventh Korea National Health and Nutrition Examination Survey (KNHANES, 2016-2018). The KNHANES is a nationwide, multistage-stratified and complex design survey on the health and nutrition of a representative sample of the entire population of Korea. It is conducted annually by trained specialists under the supervision of the Korea Centers for Disease Control and Prevention (KCDC). Data from the health questionnaire survey are collected using self-reported questionnaires. Of the 24269 participants in the 2016-2018 survey, 10586 adults aged between 40 and 70 years were initially selected. Participants who were students or unemployed or who had responded that PA in their daily lives was limited due to physical or mental disorders were excluded. Finally, 6359 participants were included in this study. Participants were missing data on PA $(n=24)$, education level $(n=1)$, income level $(n=8)$, work time $(n=11)$, working schedule $(n=10)$, occupation category $(\mathrm{n}=7)$, working status/employment type/ employment status $(n=2)$, perception of stress $(n=11)$ and source of stress $(n=3)$.

The details of the survey and dataset used in this study are available in a public, open access KNHANES repository $^{23}$ (https://knhanes.kdca.go.kr/knhanes/sub03/ sub03_02_05.do).

\section{PA assessment}

The study collected information on participants' PA levels composed of MVPA and MSA. PA levels were measured using the Korean Version of the Modified Global Physical Activity Questionnaire (K-GPAQ). The Global Physical Activity Questionnaire (GPAQ) was developed by the WHO for PA surveillance in countries and has acceptable reliability and validity. ${ }^{24}{ }^{25}$ The GPAQ was translated into a Korean version in 2013, which has established reliability and validity (kappa $0.416-0.669$, Spearman's $r$ $0.642-0.762){ }^{26}$

\section{Moderate-to-vigorous physical activity}

MVPA refers to PA performed at over 3 metabolic equivalents of task (METs; 3 METs three times the intensity of rest). The information on MVPA level was collected in three domains: OPA, transportation physical activity (TPA) and LTPA. ${ }^{27}$ OPA refers to PA undertaken during paid or voluntary work including studying and household chores. The TPA refers to PA performed to get places such as walking or cycling. LTPA is defined as PA that is not required as an essential activity of daily living such as sports, fitness and recreational activities. The total MVPA level refers to the sum of OPA, TPA and LTPA. Respondents reported their MVPA frequency (days) and duration (hours and minutes) in a typical week and were asked to report only activities that lasted for at least 10 continuous minutes. The PA level for each activity domain was estimated by multiplying the frequency by the duration. When summing the values, the minutes spent on vigorousintensity physical activity (VPA) were multiplied by two. For OPA and LTPA, moderate-intensity physical activity (MPA) and VPA were asked separately, and for TPA, only MPA was asked. The VPA refers to activities that require hard physical effort and cause large increases in breathing or heart rate (PA performed at 6 or more METs), whereas the MPA refers to activities that require moderate physical effort and cause small increases in breathing or heart rate (PA performed between 3 and $<6$ METs). Example cards showing the typical activities for each question were used to help the respondents understand the questions for consistent and valid measurements.

\section{Muscle-strengthening activities}

To assess MSA, respondents were asked, 'Over the past 7 days, how many days did you do any physical activities 


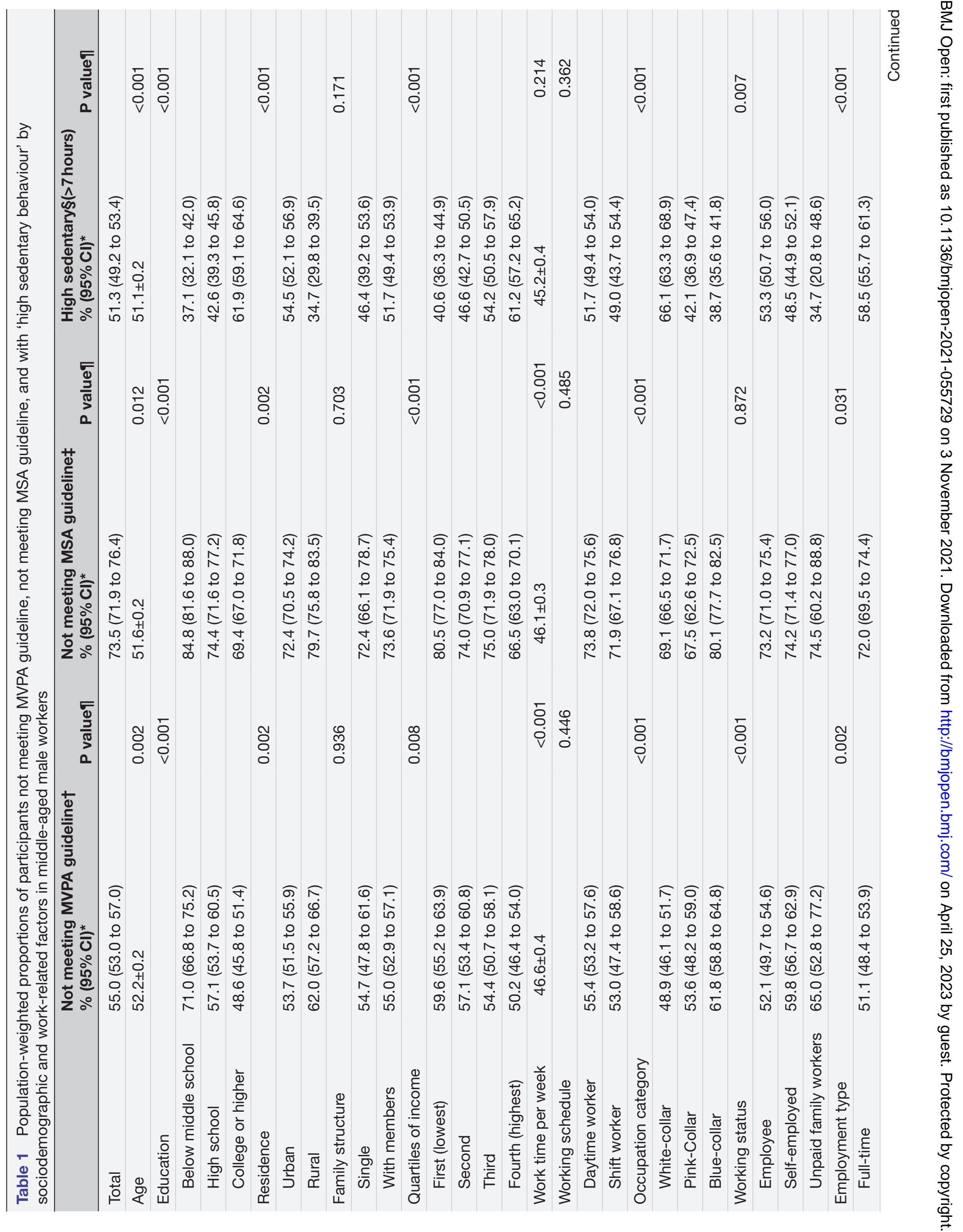




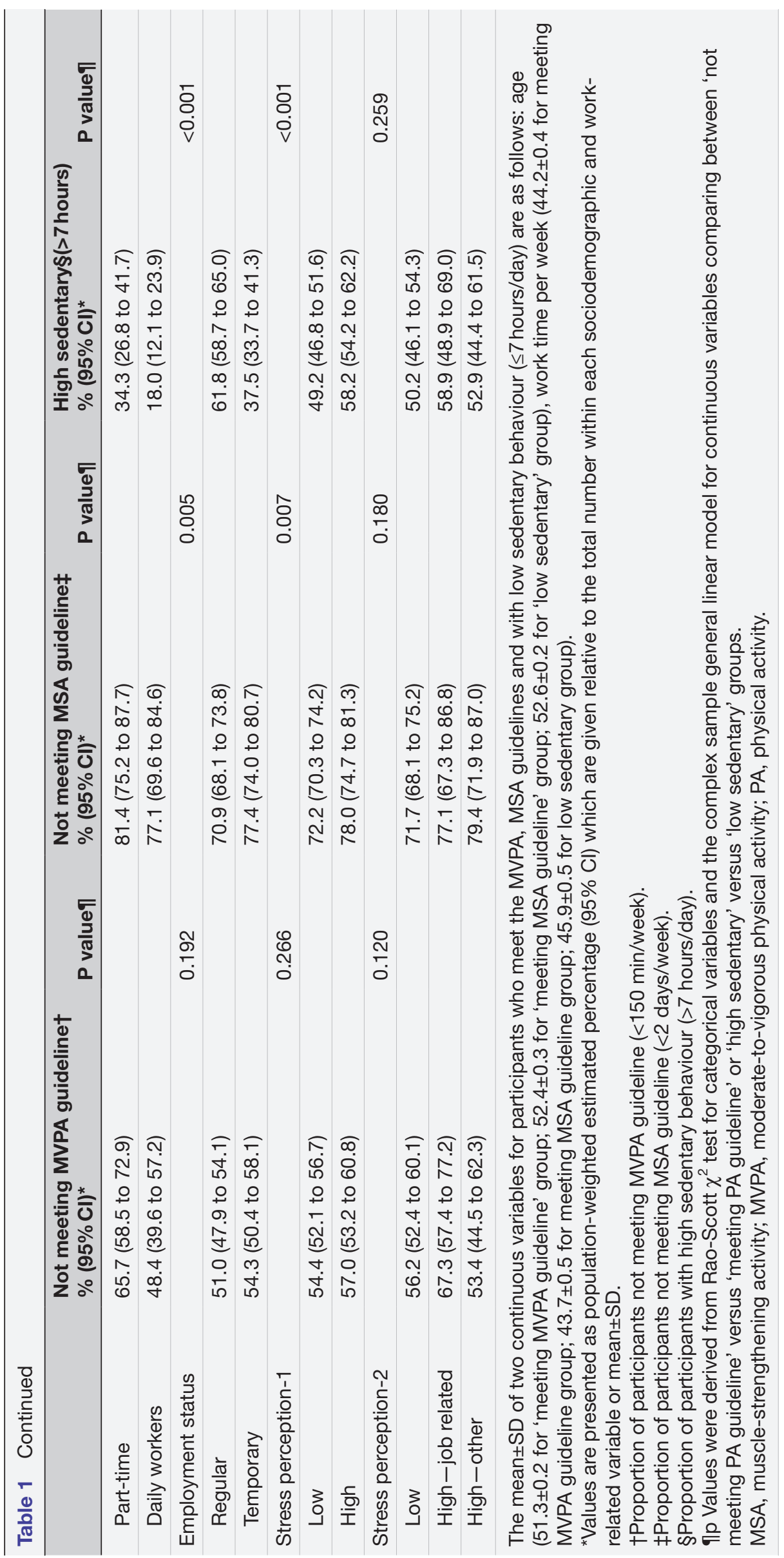




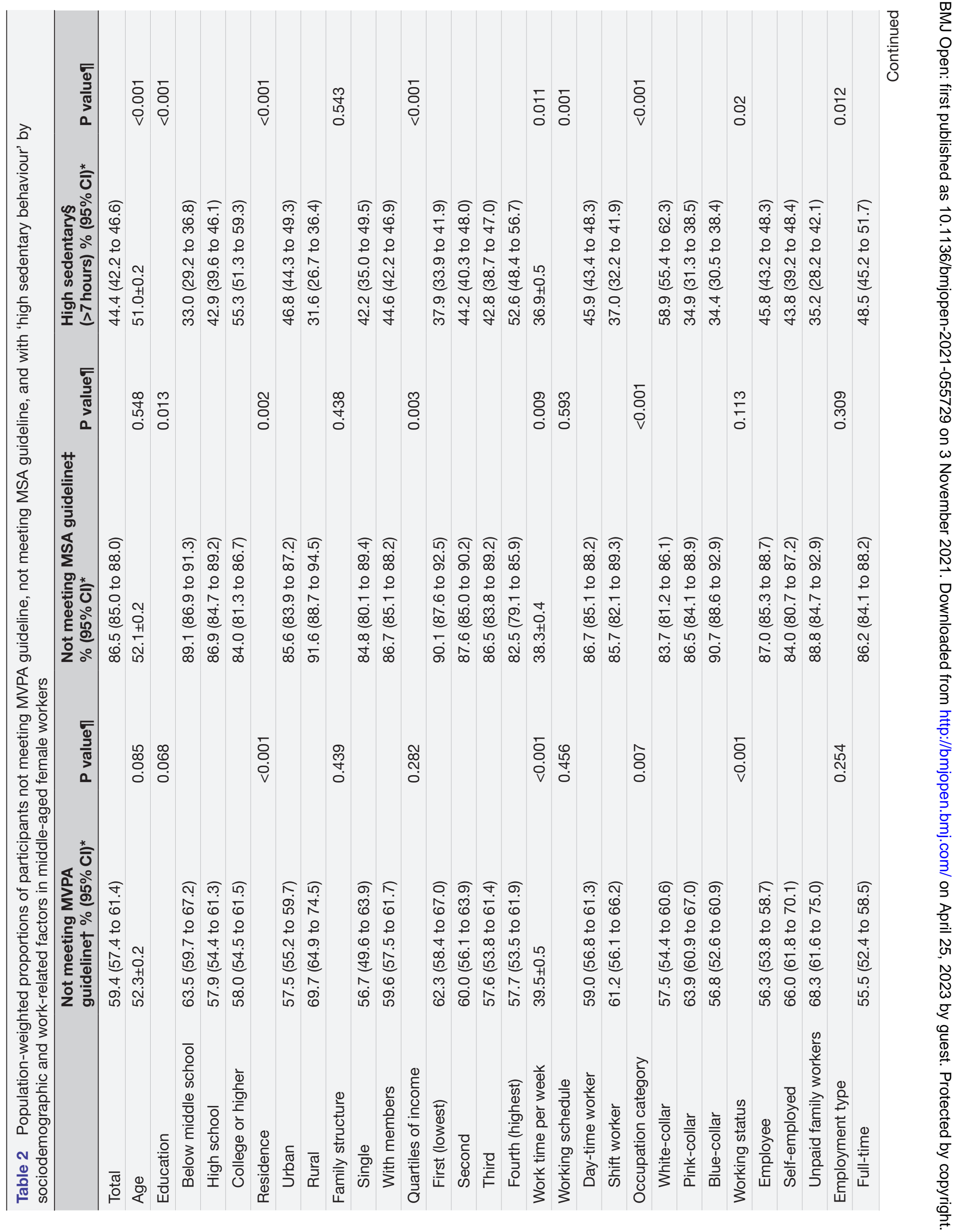




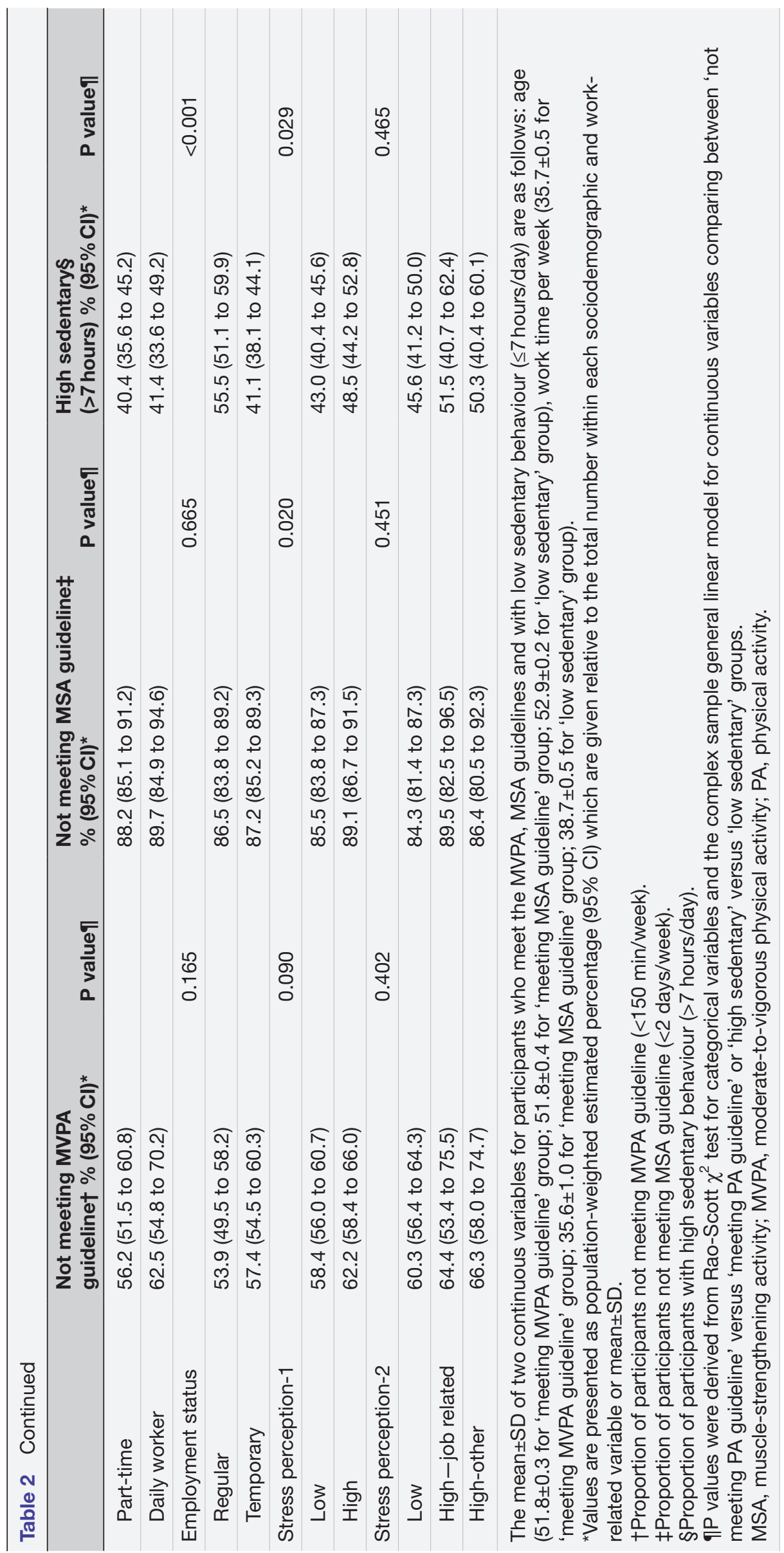


specifically designed to strengthen your muscles such as sit-ups, push-ups, lifting weights or dumbbells?'.

\section{Compliance with PA guidelines}

The 2010 WHO 'Global Recommendations on Physical Activity for Health' recommends that adults aged 18-64 years old and 65 years old and above engage in (1) $\geq 150 \mathrm{~min} /$ week of MPA, $\geq 75 \mathrm{~min} /$ week of VPA or an equivalent combination of both; and (2) MSA at a moderate or greater intensity that involves all major muscle groups on 2 or more days a week. The study's participants were dichotomised as either 'meeting the guideline' or 'not meeting the guideline', depending on their adherence to each type of PA (MVPA and MSA).

\section{Sedentary behaviours}

Sedentary behaviours are defined as behaviours with low energy expenditure $(\leq 1.5$ METs $)$ and are distinct from the simple absence of PA. ${ }^{27}$ The amount of sedentary behaviour was measured using the item in the K-GPAQ. Respondents reported their average time spent on sedentary behaviour per day during a typical week. Sedentary behaviour was defined as sitting or lying down while working, at home, moving from place to place and during leisure activities excluding sleep. We defined sedentary behaviour exceeding 7 hours a day as 'high sedentary', based on a meta-analysis showing an increased risk of all-cause mortality around 7-8 hours a day of sedentary time. $^{28}$

\section{Demographic and work-related variables}

We analysed the subjects' adherence to PA guidelines based on sociodemographic and work-related factors. The sociodemographic variables included age; sex; education level ('below middle school graduate', 'high school graduate' or 'college graduate or higher'), location of residence ('urban' or 'rural'); family structures ('singleperson household' or 'with members'); and quartiles of household income. Work-related factors included average work time per week, working schedule ('daytime worker' or 'shift worker'), occupation category ('white-collar', 'pink-collar' or 'blue-collar'); working status ('employee', 'self-employed' or 'unpaid family worker'); employment type ('full time', 'part-time' or 'daily worker'); employment status ('regular' or 'temporary'); level of stress perception 1 ('low' or 'high'); and level of stress perception 2 ('low' or 'high—job related' or 'high—other'). As for work-related variables, we collected the data based on the information about participants' 'current' occupations. In the survey, occupation was classified into 10 categories (manager, professionals and related worker, office worker, service worker, sales worker, agriculture/ forestry/fishery, craft and related trades workers, machine operators and assemblers, labour workers and soldier) according to the Korean Standard Classification of Occupation. ${ }^{29}$ We further grouped types of occupation as white-collar (manager, professionals and related worker and office worker); pink-collar (service worker and sales worker); and blue-collar (agriculture/forestry/fishery, craft and related trades workers, machine operators and assemblers and labour workers soldier). 'Stress perception' was assessed as 'high' when participants responded that they experienced 'very much' or 'much' stress. Stress perception measured overall stress regardless of stress sources. The 2018 KNHANES survey included another variable 'source of stress' composed of nine types of stress sources (ie, economic problem, job stress, family, spouse, living environment, unemployment, health, family's health, etc). The second stress perception variable (stress perception 2) was made by categorisation of high-job related, high-other, and low based on whether the stress came from job stress or not in participants with very much or much stress.

\section{Statistical analysis}

All the statistical analyses were conducted with a complex sample analysis using weights according to the KCDC's guidelines for using KNHANES' raw data. The populationweighted numbers and estimated percentages of the not meeting the guideline groups for MVPA and MSA, and the high sedentary group were calculated. The Rao-Scott $\chi^{2}$ test for categorical variables and the complex sample general linear model for continuous variables were used to test the differences between the proportions by sociodemographic factors and work-related factors. Multiple logistic regression was used to examine the odds of not meeting the MVPA guideline, not meeting the MSA guideline and high sedentary behaviour. First, we performed the analysis by adjusting for age and each related factor (model 1). Next, we performed an additional analysis by adjusting the variables that were statistically significant in model 1 (model 2). Before analysis, we assessed collinearity among all covariates we used in the analysis using tests for variance inflation factor (VIF), with a VIF $\geq 5$ indicating multicollinearity. The VIFs ranged from 1.019 to 1.938, indicating no evidence of collinearity. Analysis of covariance was used to compare the time spent on MVPA, MSA and sedentary behaviour, adjusted by sociodemographic variables that were significant in the previous analysis. The analyses were performed using SAS V.9.4, and SAS PROC SURVEY was used for complex weighting. $P$ values of $<0.05$ were considered statistically significant.

\section{Patients and public involvement}

Patients and/or the public were not involved in the design, conduct, reporting or dissemination plans of this research.

\section{RESULTS}

\section{Proportions of participants in the 'not meeting WHO PA} guidelines' and high sedentary groups

Among male workers, the proportion of participants who did not meet the guidelines was $55.0 \%$ for MVPA and $73.5 \%$ for MSA; among female workers, the proportions were $59.4 \%$ for MVPA and $86.5 \%$ for MSA. The 
proportions for high sedentary group was $51.3 \%$ in male workers and $44.4 \%$ in female workers.

\section{Differences in sociodemographic and work-related factors by PA guideline compliance and level of sedentary behaviour}

Unweighted numbers and population-weighted estimated percentages overall within each sociodemographic and work-related variable category in Korean middleaged workers are shown in online supplemental table 1. Unadjusted analyses indicated significant differences in a number of sociodemographic and work-related factors, depending on adherence to the PA guidelines (tables 1 and 2). The education level, residential area and household income were significantly associated with MVPA in men, and MSA and sedentary behaviour in both sexes. Only residential area was associated with MVPA in women. Working hours was significantly associated with MVPA, MSA in both sexes and sedentary behaviour in women. Occupation category was significantly associated with MVPA, MSA and sedentary behaviour. Stress perception was significantly associated with MSA and sedentary behaviour in both sexes, and working schedule with sedentary behaviour in women. Working status was significantly associated with MVPA in both sexes, employment type with MVPA and MSA, and employment status with MSA in men. Sedentary behaviour was significantly associated with working status, employment type and status in both sexes.

\section{Factors affecting compliance to PA guidelines}

The risk factors for 'not meeting the MVPA guideline' and 'not meeting the MSA guideline' in middle-aged workers were investigated (tables 3 and 4). Men who had been educated up to middle school (OR=2.19, 95\% CI 1.80 to 2.67) and high school graduates ( $\mathrm{OR}=1.30,95 \%$ CI 1.10 to 1.51) had a higher risk of not adhering to the MVPA guideline compared with those who had college degrees. Rural residents were less likely to meet the MVPA guideline than urban residents in both sexes (men: $\mathrm{OR}=1.27$, 95\% CI 1.06 to 1.53 ; women: OR=1.74, $95 \%$ CI 1.41 to 2.14). Workers not meeting the MVPA guideline worked longer hours than those who met the guideline $(\mathrm{OR}=1.01$, $95 \%$ CI 1.01 to 1.02). Self-employed workers of both sexes (men: $\mathrm{OR}=1.26,95 \%$ CI 1.09 to 1.47 ; women: $\mathrm{OR}=1.36$, $95 \%$ CI 1.13 to 1.64 ) and female unpaid family workers $(\mathrm{OR}=1.35,95 \%$ CI 1.02 to 1.78$)$ were at a higher risk of not meeting the MVPA guideline.

Men who had been educated up to middle school were less likely to meet the MSA guideline than those who had college degrees (OR=1.94, 95\% CI 1.31 to 2.87). Rural residents were less likely to meet the MSA guideline than urban residents (men: OR=1.43, 95\% CI 1.04 to 1.96 ; women: $\mathrm{OR}=1.65,95 \%$ CI 1.20 to 2.27 ). Men in the lowest income quartile were less likely to meet the MSA guideline than those in the highest quartile $(\mathrm{OR}=1.77,95 \%$ CI 1.26 to 2.48). Workers not meeting the MSA guideline worked longer hours than those who met the guideline ( $\mathrm{OR}=1.01,95 \%$ CI 1.00 to 1.02$)$. Female blue-collar workers were at a higher risk of not meeting the MSA guideline compared with white-collar workers $(\mathrm{OR}=1.71$, 95\% CI 1.30 to 2.24). Workers with higher stress were unlikely to practice the MSA guideline than those with lower stress (men: $\mathrm{OR}=1.43,95 \%$ CI 1.10 to 1.86 ; women: $\mathrm{OR}=1.39,95 \%$ CI 1.08 to 1.80 ).

\section{Factors affecting high sedentary behaviour}

The risk factors for high sedentary behaviour are shown in tables 3 and 4 . Male high school graduates were less likely to show high sedentary behaviour than those with college degrees $(\mathrm{OR}=0.69,95 \%$ CI 0.55 to 0.88$)$. Male rural residents were at a lower risk of high sedentary behaviour ( $\mathrm{OR}=0.57,95 \% \mathrm{CI} 0.43$ to 0.74 ). Whitecollar workers were at a greater risk of high sedentary behaviour compared with pink-collar and blue-collar workers $(\mathrm{OR}=0.40,95 \%$ CI 0.28 to 0.59 for male pinkcollar workers; $\mathrm{OR}=0.34,95 \%$ CI 0.27 to 0.44 for male blue-collar workers; OR $=0.23,95 \%$ CI 0.18 to 0.30 for female pink-collar workers; $\mathrm{OR}=0.37,95 \%$ CI 0.28 to 0.48 for female blue-collar workers). Male daily workers compared with full-time workers $(\mathrm{OR}=0.38,95 \%$ CI 0.24 to 0.59 ) and male temporary workers compared with regular workers $(\mathrm{OR}=0.75,95 \% \mathrm{CI} 0.59$ to 0.95$)$ were less likely to show high sedentary behaviour.

\section{Estimated time spent on MVPA, MSA and sedentary behaviour by occupation category, adjusted by sociodemographic factors}

The time spent on MVPA, MSA and sedentary behaviour, adjusted by age, education level, residential area and income level were compared across occupation categories (table 5 and figure 1). In both sexes, the total estimated time spent on MVPA did not differ by occupation categories. However, time spent in the occupational domain of MVPA (OPA) was significantly longer in male blue-collar workers than workers in other occupation categories in men $(\mathrm{p}<0.001)$, and time spent in the transportation domain of MVPA (TPA) was significantly longer in female blue-collar workers than pinkcollar workers $(\mathrm{p}=0.018)$. Male pink-collar workers $(\mathrm{p}=0.006)$ and female white-collar workers $(\mathrm{p}=0.004)$ spent significantly more times in MSA than blue-collar workers. White-collar workers showed significantly more sedentary behaviour than pink-collar and blue-collar workers in both sexes $(p<0.001)$.

\section{Estimated time spent on MVPA domains according to the} sedentary behaviour, adjusted by sociodemographic factors The time spent on each domain of MVPA was compared between 'low sedentary' and 'high sedentary' group. 'Low sedentary' group spent significantly longer time on OPA (men: $\mathrm{p}<0.001$; women: $\mathrm{p}=0.018)$ and TPA $(\mathrm{p}<0.001)$ than 'high sedentary' group in both sexes (online supplemental table 2).

\section{DISCUSSION}

This study assessed Korean middle-aged workers' compliance with PA guidelines and the degree of the sedentary 
Table 3 Factors associated with not meeting PA guidelines and high sedentary time in male middle-aged workers

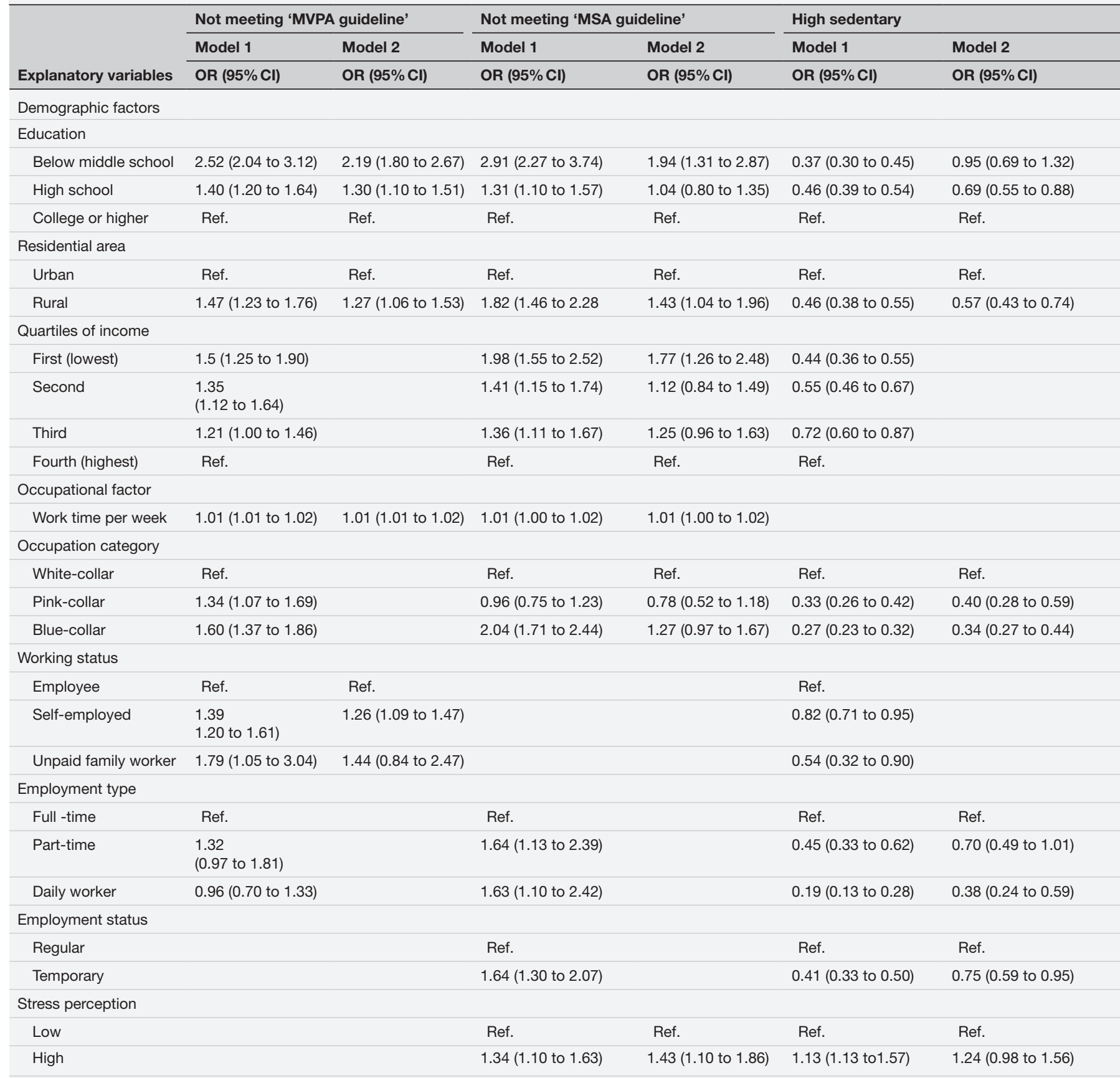

Model 1 was adjusted for age.

Model 2 was adjusted for variables that were statistically significant in model 1.

MSA, muscle-strengthening activity; MVPA, moderate-to-vigorous physical activity; PA, physical activity; Ref., reference.

behaviour in association with sociodemographic and work-related variables, particularly focusing on the influence of the occupation category. More than half of the middle-aged workers did not meet the minimum recommended level of MVPA in both sexes. The MSA compliance rate was far less than that for MVPA, especially in women, which was about half the compliance rate in men. The average time for sedentary behaviour was longer in men than in women. Compared with workers with high sedentary behaviour, workers with low sedentary behaviour spent their additional active time on OPA and TPA instead of LTPA.

The association between occupation category and total MVPA was investigated. While many previous studies focused exclusively on LTPA, this study assessed the total MVPA level to evaluate the overall MVPA status. Results showed that the differences in MVPA levels across the occupation categories became insignificant after adjusting for sociodemographic factors. This implies that sociodemographic factors are more important predictors 
Table 4 Factors associated with not meeting PA guidelines and high sedentary time in female middle-aged workers

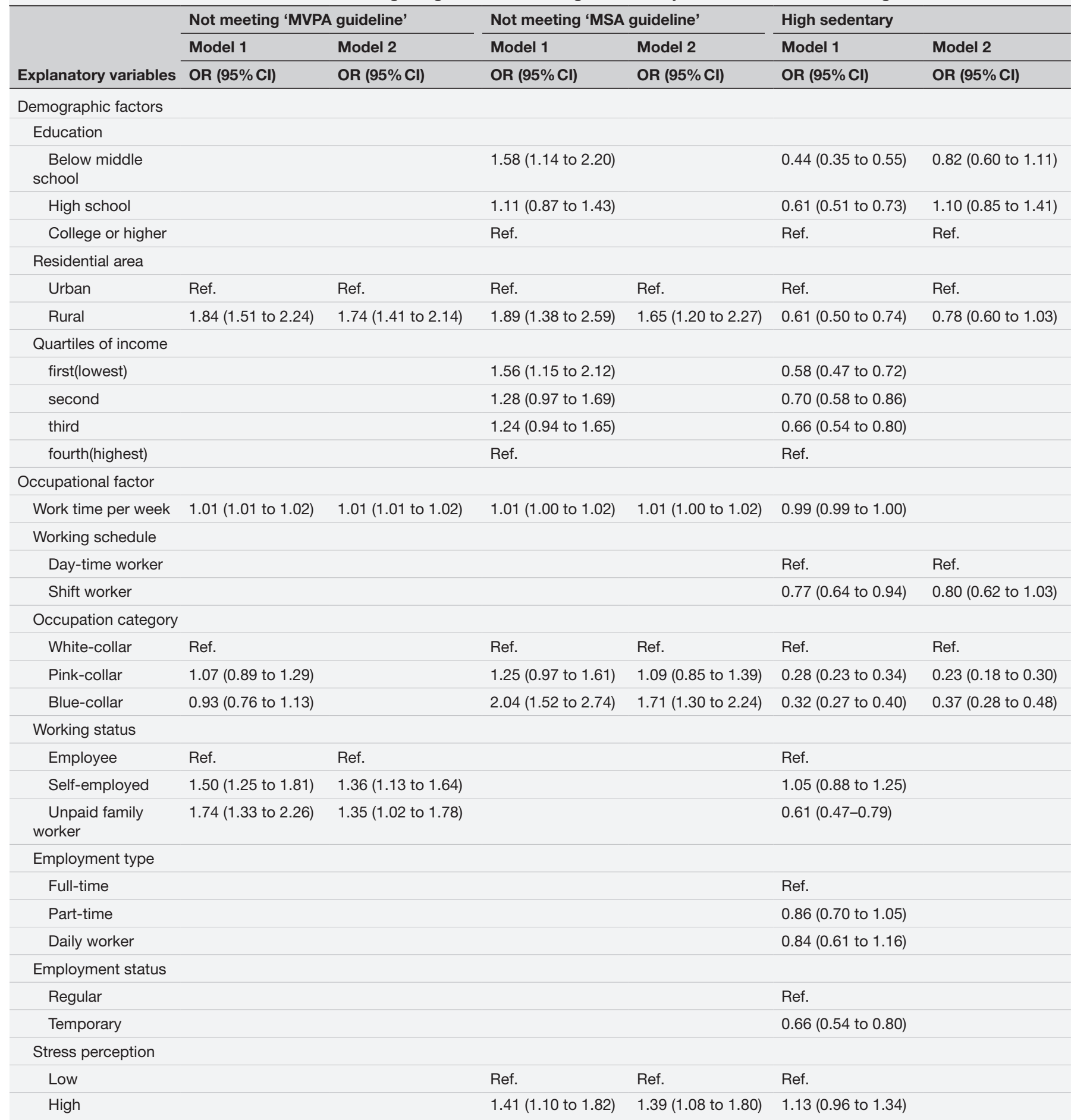

Model 1 was adjusted for age.

Model 2 was adjusted for variables that were statistically significant in model 1.

MSA, muscle-strengthening activity; MVPA, moderate-to-vigorous aerobic physical activity; PA, physical activity; Ref., reference.

of MVPA participation than occupation category. As occupation is closely intertwined with socioeconomic status, studying the association between occupation category and PA is complex, and it is important to consider the confounding effects of socioeconomic factors. ${ }^{30}$

Previous studies have shown that white-collar workers have more LTPA than blue-collar workers. ${ }^{14} \quad 15 \quad 17-19$
However, the total MVPA level was higher in blue-collar workers than in white-collar workers in all 10 studies included in a systematic review analysis. ${ }^{15}$ This was because, although the level of LTPA in blue-collar workers was lower than in white-collar workers, much higher levels of OPA in blue-collar workers resulted in higher total MVPA. ${ }^{16} 19$ This is inconsistent with our 
Table 5 Adjusted time spent for physical activity and sedentary behaviour by sex and occupational classification

\begin{tabular}{|c|c|c|c|c|c|}
\hline & White-collar & Pink-collar & Blue-collar & P value* & Post hoc \\
\hline \multicolumn{6}{|l|}{ Male } \\
\hline MVPA (min/week) & $232.4 \pm 23.6$ & $252.1 \pm 26.7$ & $283.2 \pm 22.7$ & 0.2 & \\
\hline TPA & $109.9 \pm 9.5$ & $88.3 \pm 9.4$ & $91.8 \pm 6.8$ & 0.139 & \\
\hline LTPA & $86.2 \pm 9.2$ & $101.5 \pm 14.6$ & $73.9 \pm 7.8$ & 0.250 & \\
\hline Sedentary time (min/day) & $485.3 \pm 9.1$ & $406.6 \pm 11.6$ & $394.7 \pm 7.0$ & $<0.001$ & White-pink, white-blue \\
\hline \multicolumn{6}{|l|}{ Female } \\
\hline MVPA (min/week) & $174.1 \pm 22.8$ & $159.0 \pm 12.7$ & $190.7 \pm 14.8$ & 0.1 & \\
\hline OPA & $32.8 \pm 20.6$ & $29.4 \pm 9.3$ & $38.7 \pm 9.3$ & 0.597 & \\
\hline TPA & $100.1 \pm 9.5$ & $85.4 \pm 7.7$ & $114.2 \pm 9.4$ & 0.018 & Pink-blue \\
\hline Sedentary time (min/day) & $466.0 \pm 9.4$ & $372.1 \pm 8.7$ & $377.2 \pm 8.8$ & $<0.001$ & White-pink, white-blue \\
\hline
\end{tabular}

Data are presented as mean \pm SE.

*The $p$ values are derived by analysis of covariance adjusted for age, education level, residential area and income level.

LTPA, leisure time physical activity; MSA, muscle-strengthening activity; MVPA, moderate-to-vigorous physical activity; OPA, occupational physical activity; TPA, transportation physical activity.

findings that there was no significant difference in the total MVPA and LTPA among occupation categories. In our study, male blue-collar workers did show significantly higher OPA than workers in other occupation categories, but their total MVPA levels did not significantly differ from workers in other occupations. Along with technical evolution in industry, work-related physical exertion has been declining rapidly, and OPA contributed less to total MVPA than before. ${ }^{31}$ Especially, in female workers, OPA accounted for a less significant portion, whereas TPA was the major contributor to total MVPA. While LTPA is consistently associated with positive health benefits in previous research, ${ }^{32}$ OPA remains controversial, ${ }^{33}$ with some studies even found that high OPA was associated with increased cardiovascular disease risk. ${ }^{22}{ }^{34}$ Therefore, regarding MVPA, LTPA should primarily be emphasised as a public health promotion strategy irrespective of occupation. Also, since some male blue-collar workers are still
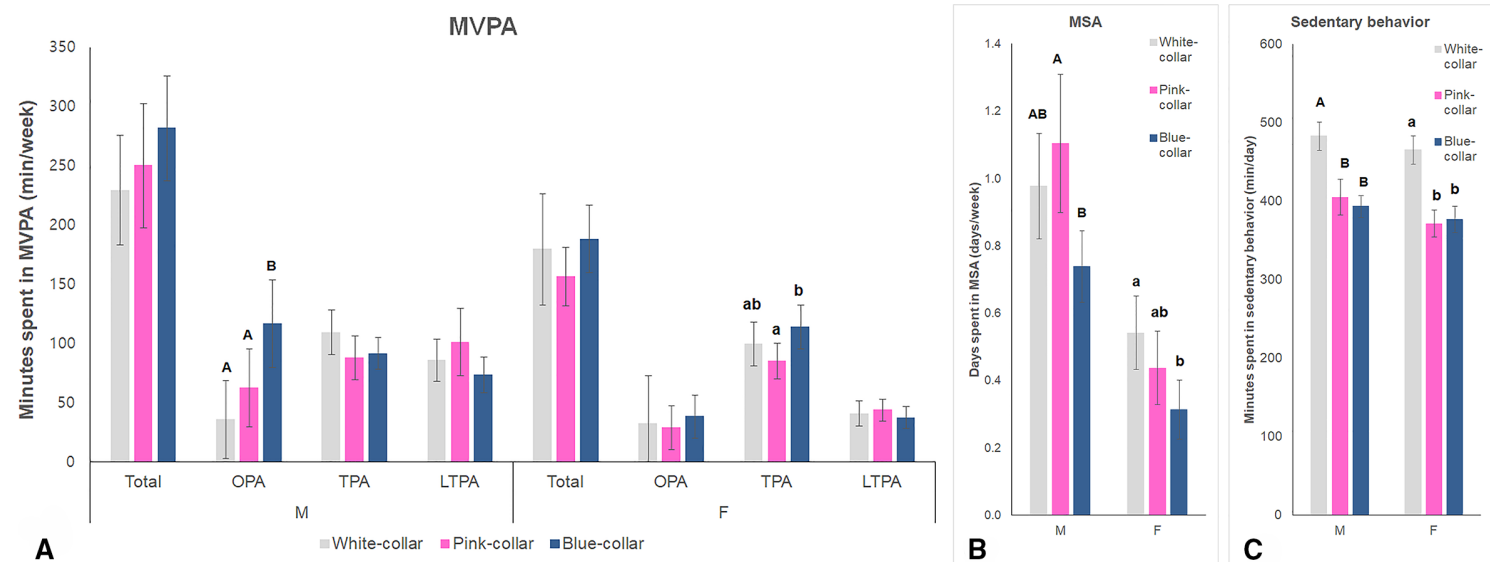

Figure 1 Comparisons of estimated time spent in MVPA (A), MSA (B) and sedentary behaviour (C) adjusted by age, education level, residential area and income level according to the type of occupation and sex in middle-aged workers in Korea. (A) For OPA, male blue-collar workers $\left(^{B}\right)$ are significantly different from white-collar $\left(^{A}\right)$ and pink-collar workers $\left.{ }^{A}\right)$. For TPA, female bluecollar workers $\left({ }^{b}\right)$ are significantly different from female pink-collar workers $\left(^{(}\right)$. (B) Male pink-collar workers $\left({ }^{A}\right)$ are significantly different from male blue-collar workers $\left({ }^{\mathrm{B}}\right)$. Female white-collar workers $\left(^{\mathrm{a}}\right)$ are significantly different from female blue-collar workers $\left({ }^{b}\right)$. Female white-collar workers $\left({ }^{a}\right)$ are significantly different from female blue-collar workers $\left({ }^{b}\right)$. (C) White-collar workers $\left({ }^{\mathrm{Aa}}\right)$ are significantly different from pink-collar and blue-collar workers $\left({ }^{\mathrm{Bb}}\right)$ in both sexes. Error bars indicate $95 \%$ Cls. LTPA, leisure-time physical activity; MSA, muscle-strengthening activities; MVPA, moderate-to-vigorous physical activity; OPA, occupational physical activity; TPA, transportation physical activity; 
exposed to high OPA, excessive OPA should be avoided for those with cardiovascular risk factors at the workplace.

The blue-collar occupations were associated with significantly lower participation in MSA compared with white-collar or pink-collar occupations. Although a limited number of studies assessed MSA participation in relation to occupation category, our findings are consistent with prior studies. ${ }^{1455}$ It should be noted that there are some differences in the questionnaire items among the different types of MSA assessment tools. ${ }^{36}$ The survey item we used in our study (How many days did you do any physical activities specifically designed to strengthen your muscles such as sit-ups, push-ups, lifting weights or dumbbells?) is likely to have only assessed MSA performed during leisure time. The MSA during work time (eg, moving heavy items, digging and construction work), on the other hand, might not have been counted when calculating the MSA level. This would have underestimated the actual level of MSA in blue-collar workers who might have accumulated some extent of MSA while working. Theoretically, attaining MSA within the occupational domain is possible and some occupational activities are associated with both MVPA and MSA. ${ }^{37}$ However, in order to obtain optimal health benefits, MSA should be performed with adequate intensity and sufficient duration using all major muscle groups, which is only possible during leisure time.

White-collar workers had the longest sedentary time among occupation categories. Excessive sitting and insufficient PA during working hours have increasingly been recognised as a public health problem. Recent accelerometry-based studies showed that occupation categories of 'office and administrative support', 'architecture/engineering' and 'computer/mathematical', which are all white-collar occupations, were among the least favourable type of job when overall activities were assessed by accelerometry. ${ }^{20} 38$ Therefore, workplace PA interventions such as using sit-stand desks and more break times to attend workplace exercise programmes should be implemented as a public health promotion strategy, particularly in white-collar workers who have the longest sedentary time. ${ }^{39}$

Work-related factors, including working hours, working schedule and stress perception, were investigated. Those who worked for longer hours reported lower levels of participation in both MVPA and MSA than those who worked fewer hours. The role of working hours is especially important as the working hours reported by Korean adults are one of the longest among the member states of the Organisation for Economic Co-operation and Development (OECD).$^{40}$ Previous evidence has indicated that working hours have a negative threshold effect on participation in MVPA, which means that the negative correlation between working hours and MVPA level becomes evident at the $45-50$ hours/week level and above. ${ }^{15}$ Shift work, compared with daytime work, did not show any association with PA level or sedentary behaviour similar to previous findings. ${ }^{19}$ This might be due to the heterogeneity present in different types of shift work (eg, shifts with or without night work, shifts with or without rotation, etc). Additionally, those who have higher overall stress participated less in MSA. Higher job strain had been shown to be associated with low PA levels in previous studies, ${ }^{15} 41$ which is inconsistent with our finding that the "higher job stress' group did not show significant difference in PA participation compared with the 'high stress from other sources' group and the 'low stress' group. Consequently, reducing working hours and helping workers manage excessive stress regardless of stress sources are important to encourage workers to be physically active.

Working status (employee/self-employed/unpaid family worker) was significantly associated with workers' MVPA level. Self-employed workers compared with employees showed significantly lower participation in MVPA. There are two contradictory views on the health of self-employed workers. ${ }^{42} 43$ One is that as selfemployed workers have the authority regarding their jobs, they demonstrate better health behaviours (eg, PA and smoking). However, the other perspective exists that they are likely to be in poor health due to high levels of job demand and work intensity. Korea, in particular, has the seventh highest proportion of self-employed workers in the working population among the 35 OECD countries, and small-sized (less than 50 workers) businesses, which have poorer working conditions than larger enterprises, ${ }^{44}$ occupy more than half of the total businesses. ${ }^{45} 46$ These negative association of self-employment and health behaviour would partly explain our result that self-employed workers demonstrated significantly lower PA levels. Employment status (full-time/part-time/ daily workers, regular/temporary) also showed a significant association with sedentary behaviours. In men, fulltime workers compared with daily workers, and regular workers compared with temporary workers engaged in sedentary behaviour for significantly longer time. Female workers also showed similar patterns but lost the statistical significance in the fully adjusted model.

\section{Strengths and limitations}

The strength of our study is that we investigated the MVPA and MSA participation and sedentary behaviour concurrently across occupation categories using national representative data. We assessed total MVPA level and sedentary behaviour together to estimate overall PA status in middle-aged workers. Our results demonstrated the different PA patterns of middle-aged workers, depending on the occupational factors, which would help develop worksite-targeted intervention. Another strength is that we took into account various sociodemographic variables during the analysis, thereby providing more adequate presentation of the association between occupation and PA levels. However, our study also has several limitations. Self-report measurement of MVPA, MSA and sedentary behaviour might have recall bias. Under-reporting or over-reporting due to social desirability is possible. However, this limitation might not significantly bias our results because the KNHANES uses standardised 
self-report instruments for public health surveillance and the recruited subject numbers were sufficient to decrease bias. The second limitation is that the inferences of causality could not have been determined because of the cross-sectional study design. Last, the data we used were limited to middle-aged individuals. However, previous studies have shown that sociodemographic correlates of PA participation change with the age of the studied population. ${ }^{47}$ Therefore, we selected the middle-aged population for a more homogenous sample of the population. Moreover, as the middle-aged population is a critical age group for the prevention of multiple chronic health conditions, our findings would help to inform health promotion policies for the targeted population.

\section{CONCLUSION}

In conclusion, work-related factors, especially occupation category, were significantly associated with MVPA, MSA, and sedentary behaviour in middle-aged workers. The workplace would offer a worthy setting for targeted interventions. As blue-collar workers are at risk of engaging in lower MSA, providing education and building facilities for MSA at work would be helpful. Worksite intervention to provide intermittent breaks to prolonged sitting is necessary for white-collar workers. Concerning MVPA, LTPA should be primarily emphasised across all occupation categories. Moreover, knowledge about work-related risk factors for physical inactivity to identify vulnerable subpopulations would help establish public health policies to reduce health inequalities.

Acknowledgements We thank the team of the Korea National Health and Nutrition Examination Survey(KNHANES) and Korea Centers for Disease Control and Prevention for providing the original KNHANES data.

Collaborators No collaborator group.

Contributors JHS conceived of the study design and wrote substantial parts of the manuscript. SRS contributed substantively to the data analysis. S-HB was responsible for quality assurance of the data and interpretation of these findings. B-JK, as a guarantor of this study, conceived of, supervised the study, and has full responsibility for the work.

Funding This work was supported by the Industrial Technology Innovation Program (serial number: 20008842) funded by the Ministry of Trade, Industry \& Energy (Korea). The funder had no roles in study design, data collection, data analysis and interpretation, or writing of the manuscript. No financial disclosures were reported by the authors of this paper.

Competing interests None declared.

Patient consent for publication Not applicable.

Ethics approval Data collection was performed after approval by the institutional review board of the Korean Centers for Disease Control and Prevention (approval number: 2018 01-03-P-A).

Provenance and peer review Not commissioned; externally peer reviewed.

Data availability statement Data are available in a public, open access repository. Data are available in a public, open access repository. The data for this study were accessed through the KNHANES homepage (https://knhanes.kdca.go.kr/knhanes/ sub03/sub03_02_05.do).

Supplemental material This content has been supplied by the author(s). It has not been vetted by BMJ Publishing Group Limited (BMJ) and may not have been peer-reviewed. Any opinions or recommendations discussed are solely those of the author(s) and are not endorsed by BMJ. BMJ disclaims all liability and responsibility arising from any reliance placed on the content. Where the content includes any translated material, BMJ does not warrant the accuracy and reliability of the translations (including but not limited to local regulations, clinical guidelines, terminology, drug names and drug dosages), and is not responsible for any error and/or omissions arising from translation and adaptation or otherwise.

Open access This is an open access article distributed in accordance with the Creative Commons Attribution Non Commercial (CC BY-NC 4.0) license, which permits others to distribute, remix, adapt, build upon this work non-commercially, and license their derivative works on different terms, provided the original work is properly cited, appropriate credit is given, any changes made indicated, and the use is non-commercial. See: http://creativecommons.org/licenses/by-nc/4.0/.

\section{ORCID iDs}

Joo Hye Sung http://orcid.org/0000-0003-2577-6350

Byung-Jo Kim http://orcid.org/0000-0002-0445-7185

\section{REFERENCES}

1 Lee I-M, Shiroma EJ, Lobelo F, et al. Effect of physical inactivity on major non-communicable diseases worldwide: an analysis of burden of disease and life expectancy. Lancet 2012;380:219-29.

2 Blair SN, LaMonte MJ, Nichaman MZ. The evolution of physical activity recommendations: how much is enough? Am J Clin Nutr 2004;79:913S-20.

3 WHO. Global recommendations on physical activity for health. Geneva: World Health Organization, 2010.

4 Ashton RE, Tew GA, Aning JJ, et al. Effects of short-term, mediumterm and long-term resistance exercise training on cardiometabolic health outcomes in adults: systematic review with meta-analysis. $\mathrm{Br}$ J Sports Med 2020;54:341-8.

5 Cruz-Jentoft AJ, Sayer AA. Sarcopenia. Lancet 2019;393:2636-46.

6 Garber CE, Blissmer B, Deschenes MR, et al. American college of sports medicine position stand. quantity and quality of exercise for developing and maintaining cardiorespiratory, musculoskeletal, and neuromotor fitness in apparently healthy adults: guidance for prescribing exercise. Med Sci Sports Exerc 2011;43:1334-59.

$7 \mathrm{Kim}$ YJ, Park H, Park JH, et al. Effects of multicomponent exercise on cognitive function in elderly Korean individuals. J Clin Neurol 2020;16:612-23.

8 Stamatakis E, Lee I-M, Bennie J, et al. Does strength-promoting exercise confer unique health benefits? A pooled analysis of data on 11 population cohorts with all-cause, cancer, and cardiovascular mortality endpoints. Am J Epidemiol 2018;187:1102-12.

9 Bauman AE, Chau JY, Ding D, et al. Too much sitting and cardiometabolic risk: an update of epidemiological evidence. Curr Cardiovasc Risk Rep 2013;7:293-8.

10 Biswas A, Oh PI, Faulkner GE, et al. Sedentary time and its association with risk for disease incidence, mortality, and hospitalization in adults: a systematic review and meta-analysis. Ann Intern Med 2015;162:123-32.

11 Chau JY, Grunseit A, Midthjell K, et al. Cross-sectional associations of total sitting and leisure screen time with cardiometabolic risk in adults. Results from the HUNT study, Norway. J Sci Med Sport 2014;17:78-84.

12 Asztalos M, Cardon G, De Bourdeaudhuij I, et al. Cross-sectional associations between sitting time and several aspects of mental health in Belgian adults. J Phys Act Health 2015;12:1112-8.

13 Wilmot EG, Edwardson CL, Achana FA, et al. Sedentary time in adults and the association with diabetes, cardiovascular disease and death: systematic review and meta-analysis. Diabetologia 2012;55:2895-905.

14 Blackwell DL, Clarke TC. Occupational differences among employed adults who Met 2008 federal guidelines for both aerobic and musclestrengthening activities: United States, 2008-2014. Natl Health Stat Report 2016;94:1-12.

15 Kirk MA, Rhodes RE. Occupation correlates of adults' participation in leisure-time physical activity: a systematic review. Am J Prev Med 2011;40:476-85.

16 Smith L, McCourt O, Sawyer A, et al. A review of occupational physical activity and sedentary behaviour correlates. Occup Med 2016;66:185-92.

17 Burton NW, Turrell G. Occupation, hours worked, and leisure-time physical activity. Prev Med 2000;31:673-81.

18 Salmon J, Owen N, Bauman A, et al. Leisure-time, occupational, and household physical activity among professional, skilled, and lessskilled workers and homemakers. Prev Med 2000;30:191-9.

19 Vandelanotte C, Short C, Rockloff M, et al. How do different occupational factors influence total, occupational, and leisure-time physical activity? J Phys Act Health 2015;12:200-7. 
20 Steeves JA, Tudor-Locke C, Murphy RA, et al. Daily physical activity by occupational classification in US adults: NHANES 2005-2006. J Phys Act Health 2018;15:900-11.

21 So W-Y, Yoo B-W, Sung DJ. The relationship between occupational status and physical activity in Korea. Soc Work Public Health 2016;31:490-7.

22 Holtermann A, Krause N, van der Beek AJ, et al. The physical activity paradox: six reasons why occupational physical activity (OPA) does not confer the cardiovascular health benefits that leisure time physical activity does. Br J Sports Med 2018;52:149-50.

23 Korea Disease Control, Prevention Agency, KDCA. Data from: the 7th Korea national health and nutrition examination survey (KNHANES, 2016-2018). public, open access KNHANES Repository. Available: https://knhanes.kdca.go.kr/knhanes/sub03/sub03_02_05.do [Accessed 06 Apr 2021].

24 Armstrong T, Bull F. Development of the world health organization global physical activity questionnaire (GPAQ). J Public Health 2006;14:66-70.

25 Bull FC, Maslin TS, Armstrong T. Global physical activity questionnaire (GPAQ): nine country reliability and validity study. $J$ Phys Act Health 2009;6:790-804.

26 Lee J, Lee C, Min J, et al. Development of the Korean global physical activity questionnaire: reliability and validity study. Glob Health Promot 2020;27:44-55.

27 Bull FC, Al-Ansari SS, Biddle S, et al. World health organization 2020 guidelines on physical activity and sedentary behaviour. $\mathrm{Br} J$ Sports Med 2020;54:1451-62.

28 Chau JY, Grunseit AC, Chey T, et al. Daily sitting time and all-cause mortality: a meta-analysis. PLoS One 2013;8:e80000.

29 Statistics Korea: korean standard classification of occupations. Available: http://kostat.go.kr/e book/kssc/KSCO07/EBook.htm

30 Hillsdon M. Occupational social class, occupational physical activity, and leisure-time physical activity. Am J Prev Med 2011;40:494-5.

31 Church TS, Thomas DM, Tudor-Locke C, et al. Trends over 5 decades in U.S. occupation-related physical activity and their associations with obesity. PLoS One 2011;6:e19657.

32 Clays E, De Bacquer D, Janssens $\mathrm{H}$, et al. The association between leisure time physical activity and coronary heart disease among men with different physical work demands: a prospective cohort study. Eur J Epidemiol 2013;28:241-7.

33 Sofi F, Capalbo A, Marcucci R, et al. Leisure time but not occupational physical activity significantly affects cardiovascular risk factors in an adult population. Eur $J$ Clin Invest 2007;37:947-53
34 Ketels M, De Bacquer D, Geens T, et al. Assessing physiological response mechanisms and the role of psychosocial job resources in the physical activity health paradox: study protocol for the Flemish employees' physical activity (FepA) study. BMC Public Health 2019;19:765

35 An K-Y. Physical activity level in Korean adults: the Korea National health and nutrition examination survey 2017. Epidemiol Health 2019;41:e2019047

36 Milton K, Varela AR, Strain T, et al. A review of global surveillance on the muscle strengthening and balance elements of physical activity recommendations. J Frailty Sarcopenia Falls 2018;3:114-24.

37 Bennie JA, De Cocker K, Smith JJ, et al. The epidemiology of muscle-strengthening exercise in Europe: a 28-country comparison including 280,605 adults. PLoS One 2020;15:e0242220.

38 Quinn TD, Pettee Gabriel K, Siddique J, et al. Sedentary time and physical activity across occupational classifications. Am J Health Promot 2020;34:247-56.

39 Batt ME. Physical activity interventions in the workplace: the rationale and future direction for workplace wellness. Br J Sports Med 2009;43:47-8

40 OECD. Hours worked (indicator), 2021. Available: http://doi.org/10. 1787/47be1c78-en

41 Kouvonen A, Vahtera J, Oksanen T, et al. Chronic workplace stress and insufficient physical activity: a cohort study. Occup Environ Med 2013;70:3-8.

42 Boyle MA, Lahey JN. Health insurance and the labor supply decisions of older workers: evidence from a U.S. department of veterans affairs expansion. J Public Econ 2010;94:467-78.

43 Rietveld CA, van Kippersluis H, Thurik AR. Self-employment and health: barriers or benefits? Health Econ 2015;24:1302-13.

44 Cocker F, Martin A, Scott J, et al. Psychological distress, related work attendance, and productivity loss in small-to-medium enterprise owner/managers. Int J Environ Res Public Health 2013;10:5062-82.

45 OECD. Self-employment rate (indicator, 2021.

$46 \mathrm{Kim} \mathrm{H}-\mathrm{J}$, Min J-Y, Min K-B. Physical and mental health problems of self-employed small business owners in South Korea. Am J Ind Med 2019;62:783-90.

47 Lee HH, Pérez AE, Operario D. Age moderates the effect of socioeconomic status on physical activity level among south Korean adults: cross-sectional analysis of nationally representative sample. BMC Public Health 2019;19:1332. 